\title{
Intra-aortic balloon pump in cardiogenic shock: state of the art
}

\section{Balão intra-aórtico no choque cardiogênico: o estado da arte}

\author{
Petronio Generoso Thomaz'; Leonel Adelino Moura Júnior ${ }^{1,2}$; Giovana Muramoto 3 ; Renato Samy Assad 4 .
}

\begin{abstract}
A B S T R A C T
The clinical definition of cardiogenic shock is that of a low cardiac output and evidence of tissue hypoxia in the presence of adequate blood volume. Cardiogenic shock is the main cause of death related to acute myocardial infarction (AMI), with a mortality rate of 45-70\% in the absence of aggressive and highly specialized technical care. The intra-aortic balloon pump (IABP) is one of the most widely used mechanical assisting devices. During the last two decades, about $42 \%$ of patients with AMI who evolved with cardiogenic shock received mechanical circulatory assistance with IABP. Its clinical indication has been based on non-randomized studies and registry data. Recent studies have shown that the use of IABP did not reduce 30-day mortality in patients with AMI and cardiogenic shock treated with the strategy of early myocardial revascularization as the planned primary objective. The guidelines of the American Heart Association and of the European Society of Cardiology have reassessed their recommendations based on the results of meta-analyzes, including the IABP-SCHOCK II Trial study, which did not evidence an increase in survival of patients who received mechanical support with IABP. This review article addresses the clinical impact of IABP use in the cardiogenic shock caused by AMI.
\end{abstract}

Keywords: Intra-Aortic Balloon Pumping. Shock, Cardiogenic. Myocardial Infarction.

\section{INTRODUCTION}

$T^{\mathrm{n}}$ he first description of the counter pulsation principle in experimental animals was made by Adrian Kantrowitz in 1952 '.

This author used the hemidiaphragm wrapped around the thoracic aorta of dogs, electrically stimulated via the phrenic nerve during the animal's diastole, producing the effect of aortic counter pulsation. In 1962, Moulopoulos et al.2, using the counter pulsation principle, developed the modern intra-aortic balloon pump (IABP), which consisted of a flask mounted on a flexible two-lumen catheter that was able to inflate and deflate in the descending thoracic aorta during each cardiac cycle. In 1968, Kantrowitz et al. ${ }^{3}$ described the hemodynamic effects of IABP use in a patient with cardiogenic shock. Cardiogenic shock is the main factor related to the mortality of acute myocardial infarction (AMI). Despite the great advances in the treatment of patients with AMI with the invasive percutaneous intervention or myocardial revascularization surgery, the mortality of cardiogenic shock remains high, with rates varying from $45 \%$ to
$70 \%{ }^{4}$. Similarly, there is little decline in the incidence of cardiogenic shock, remaining in values from $5 \%$ to $10 \%$ of AMI patients 5 . For more than two decades, IABP has been used in association with the inotropic support with vasoactive drugs, as mechanical support in cases of AMl complicated with cardiogenic shock. In this long period, the treatment of infarction has undergone considerable changes. This text will focus on the evidence for the use of IABP in the context of cardiogenic shock treatment, considering the current literature.

\section{Hemodynamic effects of IABP}

The IABP consists of a vascular catheter with a balloon mounted at its distal end. The balloon is inserted through a retrograde puncture of the femoral artery and its distal tip should be positioned in the descending thoracic aorta immediately after the emergence of the left subclavian artery (Figure 1). The tip of the catheter coincides with the pulmonary carina and should be confirmed by chest X-ray. In its adequate positioning, the helium-inflated balloon is synchronized with the cardiac cycle: inflated during diastole and deflated during systole, result-

1 - Intensive Medicine, São Paulo Holy Home, Sao Paulo, Sao Paulo State, Brazil. 2 - São Paulo County Public Servant Hospital, Cardiology Clinics, Sao Paulo, Sao Paulo State, Brazil.3 - Intensive Pediatric Medicine, Darcy Vargas Pediatric Hospital, Sao Paulo, Sao Paulo State, Brazil. 4 - Heart Institute, Clinics Hospital, School of Medicine, University of São Paulo, Surgical Laboratory of Cardiovascular Research, Sao Paulo, Sao Paulo State, Brazil. 


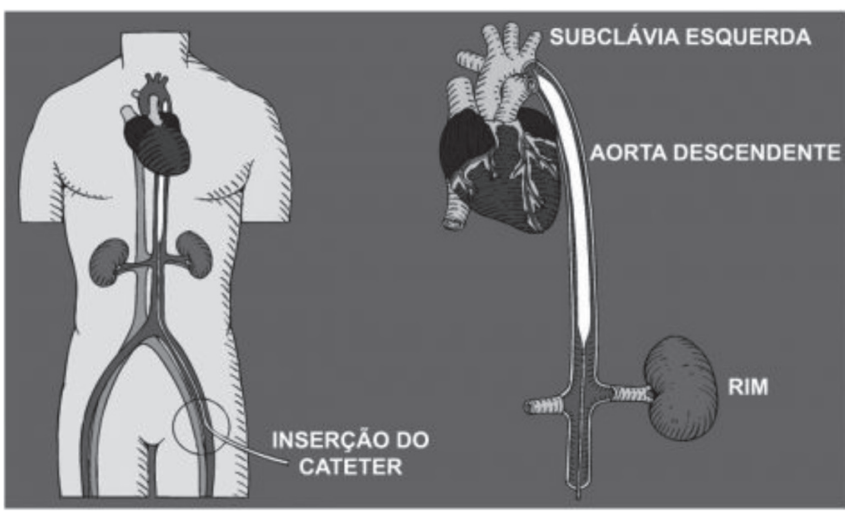

Figure 1. Proper positioning of the intra-aortic balloon.

ing in increased coronary and systemic flow during the diastolic peak (inflated IABP), reduction of the post-load and of the myocardial oxygen consumption (vacuum effect), coinciding with the rapid deinsufflation of the IABP at the beginning of systole ${ }^{6}$. Several studies evaluated the hemodynamic benefits of IABP. At baseline, most studies were unanimous in showing a reduction in systemic vascular resistance, a slight increase in cardiac index $(0.5 \mathrm{~L}$ min), and increased coronary flow ${ }^{7-9}$. Recently, observational studies with small groups of patients have shown conflicting results in assessing the influence of IABP on tissue perfusion ${ }^{10-12}$. A randomized, single-center study by Prondzinsky et al. ${ }^{13}$ compared two groups of patients with AMI complicated with cardiogenic shock. The authors did not observe significant differences in hemodynamic parameters (cardiac index, systolic work, systemic vascular resistance) in the group treated with IABP in relation to the group without IABP support.

\section{Clinical impact of IABP use}

The classic treatment strategy for ST-segment elevation AMI clearly evolved over the last decade from the fibrinolysis scenario to the primary angioplasty one. In the studies of patients with AMI without cardiogenic shock considered to be at high risk (incomplete coronary transluminal angioplasty - CTA, persistent ST elevation, Killip $>1$ ) treated with primary CTA, there was no obvious benefit with IABP circulatory assistance. Recent metaanalyzes on the subject have shown no benefit in reducing mortality, with evidence of increased incidence of stroke and bleeding ${ }^{14,15}$. There are few studies that suggest the benefit of IABP in patients with post-AMI cardiogenic shock treated with fibrinolytics. In the TACTICS study, 57 patients with $\mathrm{AMI}$ were randomized to receive thrombolytic therapy and IABP or exclusive thrombolytic therapy ${ }^{16}$. It demonstrated a positive impact of IABP associated with thrombolytic therapy in this population of patients with cardiogenic shock. It is worth highlighting the early interruption of the study due to the difficulty of patient allocation. However, these same benefits were not evidently demonstrated in patients submitted to the strategy of early percutaneous revascularization ${ }^{17,18}$. In 2009, a systematic review of the literature evaluated the use of IABP in patients with AMI and cardiogenic shock.

Table 1. Clinical outcome of the IABP Shock Trial II study (Modified by Thiele H, et al., N Engl J Med. 2012; Lancet. 2013).

\begin{tabular}{|c|c|c|c|c|c|}
\hline & & IABP & Control & $\begin{array}{l}\text { Relative risk } \\
(95 \% \mathrm{CI})\end{array}$ & $p$ value \\
\hline 30-day mortality & Total & $\begin{array}{l}119 / 300 \\
(39.7 \%)\end{array}$ & $\begin{array}{l}123 / 298 \\
(41.3 \%)\end{array}$ & $0.96(0.79-1.17)$ & 0.69 \\
\hline \multirow{2}{*}{ 30-day events } & Reinfarction & $\begin{array}{l}9 / 300 \\
(3.0 \%)\end{array}$ & $\begin{array}{c}4 / 298 \\
(1.3 \%)\end{array}$ & $2.24(070-7.18)$ & 0.16 \\
\hline & Stroke & $\begin{array}{l}2 / 300 \\
(0.7 \%)\end{array}$ & $\begin{array}{c}5 / 298 \\
(1.7 \%)\end{array}$ & $0.40(0.08-2.03)$ & 0.28 \\
\hline \multirow{3}{*}{ 12-month mortality } & Total & $\begin{array}{c}155 / 299 \\
(52 \%)\end{array}$ & $\begin{array}{c}152 / 296 \\
(51 \%)\end{array}$ & $1.01(0.86-1.18)$ & 0.91 \\
\hline & Cardiac cause & $\begin{array}{c}150 / 299 \\
(50 \%)\end{array}$ & $\begin{array}{c}148 / 296 \\
(51 \%)\end{array}$ & $1.00(0.85-1.18$ & 0.97 \\
\hline & Non-cardiac cause & $\begin{array}{l}5 / 299 \\
(2 \%)\end{array}$ & $\begin{array}{c}4 / 296 \\
(1 \%)\end{array}$ & $1.23(0.34-4.56)$ & 1.00 \\
\hline
\end{tabular}


This meta-analysis demonstrated the benefit of IABP in patients undergoing thrombolysis, but not in those submitted to primary angioplasty ${ }^{19}$. It is important to note that, in this review, observational studies were considered, mainly among the group of patients undergoing thrombolysis. More recently, Unverzagt et al. ${ }^{20}$ performed a meta-analysis that considered only randomized studies. The study included five studies, with only two of them evaluating IABP circulatory assistance. The authors did not observe any benefit of using IABP in cardiogenic shock. This lack of evidence may justify the lower indication of IABP observed in reports of large international registries, which show a rate of use in patients with cardiogenic shock between $25 \%$ and $40 \%$, despite the high levels of indications suggested in the US and European level before 2012 ${ }^{21}$. Until 2012, the European and American consensus considered the use of IABP in the scenario of post-AMI cardiogenic shock as class I (level of evidence C). Based on the results of recent meta-analyzes, current consensus has changed its recommendations to Class II-A (American Heart Association - AHA) and Class II-B (European Society of Cardiology - ESC) ${ }^{22,23}$. Currently, the European consensus does not advocate the routine use of $I A B P$, and it is recommended only as adjunctive therapy for patients with complications, such as a bridge for surgery (class II, level A evidence). In recent publications, Thiele et al.24,25 reported an elegant, prospective, randomized, multicenter study. In this study of 600 patients with cardiogenic shock secondary to AMI, they selected 301 patients for circulatory support with intra-aortic balloon (IABP group) and 299 patients as control group (without intra-aortic balloon). All patients underwent early revascularization by percutaneous intervention or surgical treatment. The primary outcome evaluated was the 30day all-cause mortality. Other secondary outcomes such as severe bleeding, peripheral ischemic complications, sepsis and stroke were also evaluated. In the final analysis at 30 days, 119 (39.7\%) patients in the IABP group and $123(41.3 \%)$ patients in the control group died (relative risk with $I A B P$ of $0.96,95 \% \mathrm{Cl} 0.79-1.17, p=0.69$ ). There were no significant differences between the IABP and the control groups regarding bleeding rates $(3.3 \%$ and $4.4 \%$, respectively; $p=0.51)$, peripheral ischemic complications
(4.3\% and 3.4, $p=0.53)$, sepsis $(15.7 \%$ and $20.5 \%$, $\mathrm{p}=0.15)$ and stroke $(0.7 \%$ and $1.7 \%, p=0.28$ ) (Table 1). The authors concluded that intra-aortic balloon use did not significantly reduce 30-day mortality in those patients with acute myocardial infarction complicated by cardiogenic shock who were submitted early to one of the revascularization strategies. At the end of 12 months, there was no reduction in all cause mortality with IABP. However, there may be benefit in patients with mechanical defects (mitral insufficiency or ventricular septal defect) or in patients with rapidly evolving shock. Some criticisms are made regarding the high crossover rate of patients in the control group for the IABP group, for reasons not associated with the development of a mechanical complication. However, once the adjusted analysis was made excluding this group of patients, there was no change in the study conclusion. There is also question about the possibility of them excluding serious patients with rapid shock deterioration, thus making the study cohort much more representative of those patients stabilized with vasopressor and/or inotropic support. Therefore, the study results may not apply to severe shock with rapid deterioration. More data and more follow-up time is needed to better understand which subgroups can benefit from using IABP. In a recent meta-analysis, seven studies totaling 790 patients with AMI and cardiogenic shock were contemplated ${ }^{26}$. The authors concluded that the available evidence demonstrates some benefit in hemodynamic parameters, but does not result in survival benefit. They then point out that there is no convincing data that supports the use of IABP in patients with cardiogenic shock after acute myocardial infarction.

\section{CONCLUSION}

The intra-aortic balloon remains the minimally invasive circulatory assistance device most commonly used by intensivists for cases of AMl complicated by cardiogenic shock. However, current evidence does not support its routine use in the majority of this population. This circulatory care device may have beneficial effects on some hemodynamic parameters, however, without impact on hospital and late survival. 


\title{
R E S U M O
}

\begin{abstract}
A definição clínica de choque cardiogênico é a de um quadro de baixo débito cardíaco e evidência de hipóxia tecidual, na presença de volemia adequada. O choque cardiogênico representa a principal causa de óbito relacionada ao infarto agudo do miocárdio (IAM), com índice de mortalidade em torno de $45 \%$ a $70 \%$, na ausência de cuidados técnicos agressivos e altamente especializados. O balão intra-aórtico (BIA) é um dos dispositivos de assistência mecânica mais utilizados no mundo. Nas duas últimas décadas, cerca de $42 \%$ dos pacientes com IAM, que evoluíram com choque cardiogênico, receberam assistência circulatória mecânica com BIA. Sua indicação clínica tem sido baseada em estudos não randomizados e dados de registro. Estudos recentes têm demonstrado que o uso do BIA não reduziu a mortalidade hospitalar (30 dias) em pacientes com IAM e choque cardiogênico, tratados com a estratégia de revascularização precoce do miocárdio como objetivo primário planejado. As diretrizes da Associação Americana de Cardiologia e da Sociedade Europeia de Cardiologia reavaliaram suas recomendações, baseadas nos resultados de metanálises, incluindo o estudo IABP-SCHOCK II Trial, que não evidenciou aumento na sobrevida de pacientes que receberam suporte mecânico com BIA. Este artigo de revisão aborda o impacto clínico do uso do BIA no choque cardiogênico ocasionado pelo IAM.
\end{abstract}

Descritores: Balão Intra-Aórtico. Choque Cardiogênico. Infarto do Miocárdio.

\section{REFERENCES}

1. Kantrowitz A. Experimental augmentation of coronary flow by retardation of the arterial pressure pulse. Surgery. 1953;34(4):678-87.

2. Moulopoulos SD, Topaz S, Kolff WJ. Diastolic balloon pumping (with carbon dioxide) in the aorta -- a mechanical assistance to the failing circulation. Am Heart J. 1962;63:669-75.

3. Kantrowitz A, Tjonneland S, Freed PS, Phillips SJ, Butner AN, Sherman JL. Initial clinical experience with intraaortic balloon pumping in cardiogenic shock. JAMA. 1968;203(2):113-8.

4. Jeger RV, Radovanovic D, Hunziker PR, Pfisterer ME, Stauffer JC, Erne P, et al. Ten-year trends in the incidence and treatment of cardiogenic shock. Ann Intern Med. 2008;149(9):618-26.

5. Goldberg RJ, Spencer FA, Gore JM, Lessard D, Yarzebski J. Thirty-year trends (1975 to 2005) in the magnitude of, management of, and hospital death rates associated with cardiogenic shock in pacients with acute myocardial infarction: a population-based perspective. Circulation. 2009;119(9):1211-9.

6. Kern MJ, Aguirre F, Bach R, Donohue T, Siegel R, Segal J. Aumentation of coronary blood flow by intra-aortic balloon pumping in patients after coronary angioplasty. Circulation. 1993;87(2):500-11.

7. Mueller H, Ayres SM, Conklin EF, Giannelli S Jr, Mazzara JT, Grace WT, et al. The effects of intra-aortic counterpulsation on cardiac performance and metabolism in shock associated with acute myocardial infarction. J Clin Invest. 1971;50(9):1885-900.
8. Scheidt S, Wilner G, Mueller H, Summers D, Lesch M, Wolff $G$, et al. Intra-aortic balloon counterpulsation in cardiogenic shock. Report of a co-operative clinical trial. N Engl J Med. 1973;288(19):979-84.

9. Shaw J, Taylor DR, Pitt B. Effects of intraaortic balloon counterpulsation on regional coronary blood flow in experimental myocardial infarction. Am J Cardiol. 1974;34(5):552-6.

10. MacDonald RG, Hill JA, Feldman RL. Failure of intraaortic balloon counterpulsation to augment distal coronary perfusion pressure during percutaneous transluminal coronary angioplasty. Am J Cardiol. 1987;59(4):359-61.

11. Jung $C$, Rödiger $C$, Fritzenwanger $M$, Schumm J, Lauten $A$, Figulla HR, et al. Acute microflow changes after stop and restart of intra-aortic ballon pump in cardiogenic shock. Clin Res Cardiol. 2009:98(8);469-75.

12. Munsterrman LD, Elbers PW, Ozdemir A, van Dorgen EDP, van Iterson $\mathrm{M}$, Ince $\mathrm{C}$. Whitdrawing intra-aortic ballon pump support paradoxically improves microvascular flow. Crit Care. 2010;14(4):R161.

13. Prondzinsky R, Unverzagt $S$, Russ $M$, Lemm H, Swyter M, Wegener $N$, et al. Hemodynamic effects of intra-aortic ballon counterpulsation in patients with acute myocardial infarction complicated by cardiogenic shock: the prospective, randomized IABP shock trial. Shock. 2012;37(4):378-84.

14. Bahekar A, Singh M, Singh S, Bhuriya R, Ahmad K, Khosla S, et al. Cardiovascular outcomes using intra-aortic balloon pump in high-risk acute myocardial infarction with or without cardiogenic shock: a meta-analysis. J Cardiovasc Pharmacol Ther. 2012;17(1):44-56. 
15. Cassese S, de Waha A, Ndrepepa G, Ranftl S, King L, Schömig A, et al. Intra-aortic balloon counterpulsation in patients with acute myocardial infarction without cardiogenic shock. A meta-analysis of randomized trials. Am Heart J. 2012;164(1):58-65.

16. Ohman EM, Nanas J, Stomel RJ, Leesar MA, Nielsen DW, O'Dea D, et al. Thrombolysis and counterpulsation to improve survival in myocardial infarction complicated by hypotension and suspected cardiogenic shock or heart failure: results of the TACTICS Trial. J Thromb Thrombolysis. 2005;19(1):33-9.

17. Barron HV, Every NR, Parsons LS, Angeja B, Goldberg RJ, Gore JM, et al. The use of intra-aortic balloon counterpulsation in patients with cardiogenic shock complicating acute myocardial infarction: data from the National Registry of Myocardial Infarction 2. Am Heart J. 2001;141(6):933-9.

18. Cheng JM, Valk SD, den Uil CA, van der Ent M, Lagrand $W K$, van de Sande $M$, et al. Usefulness of intra-aortic balloon pump counterpulsation in patients with cardiogenic shock from acute myocardial infarction. Am J Cardiol. 2009;104(3):327-32.

19. Sjauw $K D$, Engström $A E$, Vis $M M$, van der Schaaf RJ, Baan J Jr, Koch KT, et al. A systematic review and meta-analysis of intra-aortic balloon pump therapy in ST-elevation myocardial infarction: should we change the guidelines? Eur Heart J. 2009;30(4):459-68.

20. Unverzagt S, Machemer MT, Solms A, Thiele $H$, Burkhoff $D$, Seyfarth $M$, et al. Intra-aortic balloon pump counterpulsation (IABP) for myocardial infarction complicated by cardiogenic shock. Cochrane Database Syst Rev. 2011;(7):CD007398.

21. Thiele H, Allam B, Chatellier G, Schuler G, Lafort A. Shock in acute myocardial infarction: the Cape Horn for trials? Eur Heart J. 2010;31(15):1828-35.

22. O'Gara PT, Kushner FG, Ascheim DD, Casey DE Jr, Chung MK, de Lemos JA, et al. ACCF/AHA guide- line for management of ST-elevation myorcadial infarction: a report of the American College of Cardiology Foundation/American Heart Association Task Force on Practice Guidelines. Circulation. 2013;127(4):e362-425. Erratum in: Circulation. 2013;128(25):e481.

23. Task Force on the management of ST-segment elevation acute myocardial infarction of the European Society of Cardiology (ESC)., Steg PG, James SK, Atar D, Badano LP, Blömstrom-Lundqvist $C$, et al. ESC Guidelines for the management of acute myocardial infarction in patients presenting with ST-segment elevation. Eur Heart J. 2012;33(20):2569619.

24. Thiele H, Zeymer U, Neumann FJ, Ferenc M, Olbrich HG, Hausleiter J, et al. Intraaortic balloon support for myocardial infarction with cardiogenic shock. N Engl J Med. 2012;367(14):1287-96.

25. Thiele H, Zeymer U, Neumann FJ, Ferenc M, Olbrich HG, Hausleiter J, et al. Intra-aortic balloon counterpulsation in acute myocardial infarction complicated by cardiogenic shock (IABP-SHOCK II): final 12 month results of a randomised, open-label trial. Lancet. 2013;382(9905):1638-45.

26. Unverzagt $S$, Buerke $M$, de Waha A, Haerting J, Pietzner $D$, Seyfarth $M$, et al. Intra-aortic balloon pump counterpulsation (IABP) for myocardial infarction complicated by cardiogenic shock. Cochrane Database Syst Rev. 2015;(3):CD007398.

Received in: 15/09/2016

Accepted for publication: 03/11/2016

Conflict of interest: none.

Source of funding: none.

\section{Mailing address:}

Petronio Generoso Thomaz

E-mail: petroniogt@gmail.com / petronio@sbccv.org.br 